\title{
FORMACIÓN GENERAL, NECESIDAD DEL CURRÍCULO UNIVERSITARIO'
}

\author{
Walter Peñaloza Ramella
}

\section{ALGUNAS PRECISIONES FUNDAMENTALES}

En el presente texto vamos a ocuparnos de la formación General en los currícula universitarios. Más acontece que la noción de Formación General se halla oscurecida por una serie de ideas y definiciones poco afortunadas que han generado confusión entre los profesores universitarios. Conviene por ello deslindar conceptos y separar lo que es Formación General y distinguirla de otras estructuras curriculares con las cuales a veces se la mezcla indebidamente.

\section{A. UNA NOCIÓN PROVISORIA}

Con carácter negativo, y, por lo mismo, de manera insatisfactoria, podemos comenzar aseverando que los componentes curriculares que constituyen la Formación General se diferencias de otros componentes, archiconocidos, que sirven a cada una de las carreras universitarias y proporcionan a los alumnos los conocimientos científicos que ellas requieren.

Los componentes de Formación General no prestan servicio a ninguna carrera. En vano, buscar en ellos principios y leyes que específicamente ayuden en las tareas de los ingenieros, o de los médicos, o de los sociólogos, o de otras profesiones.

Se configuran así dos grandes tipos de componentes curriculares: los de Formación General y los de Formación Profesional. Los primeros, desasidos de las carreras, pero válidos para todas ellas (y por eso el nombre de Formación General). Los segundos, vinculados a cada carrera, sean como cursos iniciales, fundamentales o introductorios (mejor denominados "Propedéuticos"), sea como cursos específicos (propios de cada carrera). De éstos últimos (los segundos) podemos decir, por tanto, que se subdividen en asignaturas de formación Profesional Básica (o Propedéutica) y en asigna-turas de Formación Profesional Específica: un y otras constituyen las dadoras de los conocimientos que cada profesión requiere; las 
propedéuticas, brindando la plataforma inicial de cada carrera; las específicas, proveyendo los conocimientos de cada una. En contraposición a los cursos básicos y específicos de la Formación Profesional, las asignaturas de Formación General no tienen que ver con ninguna carrera. No proporcionan conocimientos ni habilidades que concretamente sean utilizables en ninguna de ellas. Surge inevitablemente una pregunta iPor qué entonces debe incluirse la Formación General en los currícula universitarios?

A primera vista, si no se relaciona con profesión alguna, no existe necesidad de ella. Y así juzgan, en efecto, bastantes profesores universitarios a quienes se escucha aseverar que la Formación General, puesto que no es útil a ninguna carrera, viene a ser en definitiva una pérdida de tiempo.

\section{B. UNA VISIÓN MÁS PROFUNDA}

Si nos acercamos a delinear una noción positiva de la formación General, tratando de encontrar sus propósitos, descubrimos que ella, pese a no aportar elementos que sirvan a las carreras, ostenta irrefragable derecho a ser ubicada en todos los planes curriculares sin excepción.

¿Qué persigue la formación General? En esencia dos cosas (a) proporcionar a los alumnos universitarios ciertas consideraciones y determinadas herramientas que los conviertan en reales estudiantes universitarios; y (b) mostrarles los grandes problemas que atañen a la humanidad, al mundo, a nuestra época y a nuestro país. El propósito (a) conforma la periferia de la Formación General; el propósito (b) es el corazón de la Formación General.

Sobre estas dos partes de la formación General hablaremos más detenidamente después. Digamos por ahora que ser alumno universitario no consiste solamente en haber rendido una prueba de ingreso y haber sido admitido en la Universidad. Los muchachos y muchachas que acceden a los claustros universitarios requieren ante todo hacer suyo el lenguaje académico, consustancial con las tareas universitarias, tanto en amplitud como en profundidad, más a lo que parece, la mayor parte de las universidades rehúsa incluir en los currícula de sus carreras, por ejemplo, seminarios o talleres de lenguaje, so pretexto de que el lenguaje lo aprendieron los alumnos en la etapa escolar. Olvidan que con respecto al lenguaje cada etapa del sistema educativo tiene su propia responsabilidad y que no es la Secundaria la llamada a brindarles a los adolescentes el lenguaje universitario. Asimismo, los alumnos universitarios requieren ciertas reflexiones sobre capacidades humanas que están en ellos y que las Universidades se encuentran obligadas a sacar a claridad teorética. Nos referimos a las capacidades de aprender, de pensar, de investigar, de conocer y a una visión de la vida sicológica. 
Más por sobre todo ello reside la problemática que incide en el ser del hombre: cómo los humanos hemos enfrentado al universo que nos rodea; qué representamos en la esfera biológica; cuál es nuestra situación en la realidad social y económica en este planeta que nos llenamos la boca en aseverar que es globalizado pero que nos abstenemos de analizar para saber cómo es; y, cuán actual y desarrollado y lleno o falto de equidad es nuestro país. Nada de esto es verbalismo ni ocioso escarceo. Al contrario, nos va en ello lo más serio de nuestra vida y lo más trascendente de nuestra posible acción futura. De otro modo, graduamos y graduaremos miles de abogados, economistas, ingenieros, químicos, educadores, agrónomos, médicos, mas profesionales premunidos de muchos conocimientos de sus respectivas carreras, pero ciegos para lo más profundo de sus vidas y para las realidades de nuestra nación, y carentes - como, lamentablemente viene ocurriendo - del mínimo nivel expresivo y cultural aceptable que toda persona salida de una Universidad debe poseer.

\section{LA FORMACIÓN GENERAL NO LA DA LA SECUNDARIA}

Hay quienes creen que la formación General es algo así como las antiguas "lecciones de cosas", una suerte de miscelánea de datos e informaciones variadas procedentes de diversas disciplinas. Y como consecuencia sostienen muy orondos, que la Formación General los alumnos ya la han recibido en la Secundaria. Y, por eso mismo, resulta innecesaria en el nivel universitario. Los que abrigan semejante idea revelan no comprender lo que es la etapa escolar previa a la Universidad y lo que es la Universidad. La Primaria y la Secundaria (o, en su lugar, la Educación Básica) no proporcionan Formación General. La etapa escolar, en el aspecto intelectual, intenta un acercamiento de los niños y adolescentes al mundo físico, social e histórico circundante y más lejano. Les provee de un inventario de la realidad. Y en el orden no intelectual -por desgracia, el más olvidado- les ofrece, o debería ofrecerles, el ejercicio de una mente despierta y ágil para afrontar la vida, para ser buenos ciudadanos y para asumir la cultura de su continuidad.

Pero nada de esto, propio de la etapa escolar, constituye Formación General, porque la Formación General, no es un inventario de la realidad, ni escueto ni más detallado, sino una reflexión sobre tal realidad. Puede haber nuevos hechos, pero la Formación General no consiste en acopiarlos, sino en interpretarlos y ponerlos en una perspectiva comprensiva. $Y$ eso no lo puede hacer la etapa escolar, porque el nivel de maduración de los adolescentes no lo permite. Pero sí es la obligación de las instituciones de educación superior. Resulta más bien grave que los jóvenes pasen cinco años en la Universidad y egresen como salieron de la Secundaria, con un inventario de la realidad, y con información científica de su carrera y nada más. Seres incompletos, no enteramente formados, y en el mejor de los casos, puros tecnócratas. 
Desechemos, pues, la idea de que es la Secundaria la que da la Formación General. La Formación General, por su naturaleza, es cosa de las universidades.

\section{LOS CURSOS DE FORMACIÓN GENERAL NO SON LOS CURSOS BÁSICOS (O PROPEDÉUTICOS)}

Una confusión de que a menudo se incurre es considerar que la Formación General se halla constituida por los cursos básicos que toda carrera necesita.

Los cursos básicos son aquellos de carácter introductorio o preliminar que algunas carreras incluyen en sus currícula (p.ej.: Introducción al Derecho, Elementos de Sociología, Principios de Electricidad, Matemática Básica, etc.), o bien materias que sirven de cimiento (de ahí el nombre de "básicas") y/o de apoyo a las asignaturas ulteriores propias de cada carrera (p.ej.: Biología, Sicología, Matemática I, II, III, etc., Física, Bioquímica, Termodinámica, Métodos Numéricos, Electromagnetismo, etc.). En una palabra, los cursos básicos sirven a una carrera; (a veces, a varias carreras; $y$ otras, a muchas).

De ahí que la diferencia con los cursos de Formación General sea nítida porque estos no se hallan al servicio de ninguna carrera, no son introductorios con relación a estas, ni ponen los cimientos para ninguna carrera.

Por lo mismo que los cursos básicos están ligados a ésta o aquella profesión, tales cursos básicos son parte de la Formación Profesional, y no de la Formación General. Integran la Formación Profesional Básica (o mejor, Propedéutica). Y, como es obvio, todas las asignaturas de la Formación Profesional Básica conjuntamente con las de la Formación Profesional Específica coadyuvan a la preparación de los alumnos con vistas a su certificación en una carrera.

Los cursos de Formación General, en cambio, son la contrapartida de la Formación Profesional en cuanto proporcionan los horizontes humanísticos (letras y ciencias), más allá de la Formación Profesional. Esta brinda a los alumnos los conocimientos (Propedéuticos y Específicos), que su carrera demanda. La Formación General, en cambio, Les da los fundamentos que, como hombres de esta época y de este país, necesitan.

Con respecto a la Formación Profesional Básica o Propedéutica se dan en la práctica tres errores muy comunes.

i) Pensar que los cursos de Formación Profesional Básica reemplazan a la Formación General y cumplen igual o parecido papel. Esto, quizás porque algunos de tales cursos son comunes a varias carreras o a muchas. Y así hay 
Universidades que han organizado un conjunto de materias como Biología, Física, Cálculo Diferencial e Integral, Sociología, Química, etc., y las establecen en todas sus carreras, sin percatarse de que estas asignaturas sólo deben incluirse en una carrera si es que van a brindarle contenidos indispensables para el desarrollo de sus materias específicas. En estos casos se está empleando lo que pertenece a una carrera y/o a diversas carreras (en cuanto les proporcionan ciertas bases) como si fuera algo general. Se genera de este modo un conflicto de finalidades, pues lo que es particular para como general. $Y$, lo que es peor, los alumnos sufren porque tienen que estudiar asuntos que no les competen.

ii) Más grave es lo que acontece cuando las asignaturas de Formación Profesional Básica (sea en la forma espúrea expuesta en el acápite anterior -absurdamente general- sea en la forma correcta de coadyuvante a la preparación de una determinada carrera) se desarrollan, sin embargo, con independencia de cada carrera. Se produce aquí una paradoja verdaderamente inadmisible: lo que por naturaleza debe encontrarse al servicio de una carrera, es presentado por los profesores a los alumnos como una materia válida por si, y desconectada de la carrera, a la cual debería servir.

Esta situación atormenta a los alumnos, quienes no alcanzan a percibir la ayuda que semejantes cursos así dictados les prestan en sus carreras y suscita la protesta de los profesores de los cursos específicos que no ven enfatizados en las asignaturas básicas los temas que ellos necesitan.

Uno de los factores contribuyentes al fracaso, en muchas Universidades, de la departamentalización que la Ley $N^{\circ} 17437$ introdujo en el sistema universitario del Perú fue precisamente que los departamentos creyeron ser los dueños de las ciencias básicas y las impartían, no según los requerimientos de cada carrera, sino según su criterio puramente científico (no "para", sino "en si").

Los departamentos no tuvieron en cuenta que en ese sistema matricial los programas (o sea, las carreras) mandan y los departamentos sirven. Las cosas acontecieron al revés y ello creó una atmósfera adversa a la departamentalización, a tal punto que más tarde pareció un progreso retornar al sistema facultativo.

El daño no fue menor para los currícula. Estos, que teóricamente debían ser hechos por los programas (pues cada carrera sabe lo que le conviene), se convirtió en lucha entre los departamentos, ya que cada uno quería imponer 
mayor número de materias en los planes curriculares. De esta manera los currícula eje de cada carrera y del trabajo universitario, en lugar de responder a una concepción coherente de lo que la respectiva profesión es, devinieron en mezclas heterogéneas, producto del tira y afloja entre los departamentos.

Todos estos males nacieron y nacen que la palabra "básico" no es unívoca. En sentido epistemológico las ciencias básicas son las ciencias puras, las cuales valen por sí mismas, se desentienden en toda aplicación, y no se sienten atadas a ninguna carrera. En sentido curricular las ciencias básicas son las que desbrozan el terreno que ha de facilitar el desarrollo de las materias específicas de cada carrera. El error consiste en tomar las materias básicas incluidas en un vitae correctamente en sentido curricular como si fueran disciplinas básicas en sentido epistemológico. Cesa entonces lo que es "para" y resulta convertido en "en sí". Por esta razón vamos a utilizar a partir de ahora, no el término "básico" (que puede malinterpretarse), sino el término "propedéutico", cuyo sentido subraya el servicio que una materia ha de prestar a una carrera, otorgándole las bases para sus asignaturas específicas. Hablamos pues de "cursos propedéuticos" de cada profesión; y hablamos también de "Formación Profesional Propedéutica" y de "Formación Profesional Específica".

iii) Otro error es mezclar los cursos de Formación General con los cursos de Formación Profesional Propedéutica, o al menos con algunos de ellos, y entregar semejante conjunto a una determinada estructura académica para que ejecute su administración. En efecto, es plausible que dentro de una Universidad exista un ente a cargo de las asignaturas de Formación General, pero es equivocado que se le adscriban todas o siguiera algunas de las materias propedéuticas. Por qué ese ente tenderá a impartir tales materias de manera separada de los fines de cada carrera, esto es, en sentido epistemológico y no curricular. Y ello ocurrirá por la sencilla razón de que dicho ente, por esencia, no está llamado a tener en cuenta las necesidades particulares de las distintas carreras. En realidad, se está forzando a la estructura o ente académico a cargo de la Formación General a desempeñar un rol para el cual esa estructura no ha sido creada. Por su naturaleza, ella no está obligada a tener en cuenta las especificidades de las carreras.

Por lo demás cada carrera sabe dónde le aprieta el zapato, y resulta palmario que el contenido de las asignaturas propedéuticas que les son indispensables sea definido por ellas. El Departamento (o la Facultad) que tenga que impartirlas ha de hacerlo dentro del marco y/o temática que le ha sido señalada por cada carrera. No se ve, por tanto, ninguna razón para que la entidad que maneja los cursos de Formación General deba ocuparse de todas o algunas 
de las disciplinas propedéuticas, cuyo sentido es diametralmente opuesto a las materias de Formación General.

\section{E. LOS CURSOS DE FORMACIÓN GENERAL NO SON SINO TANGENCIALMENTE LOS CURSOS DE OTRAS CARRERAS}

Existe también la creencia de que, pues la Formación General airea la mente de los alumnos universitarios, el tomar materias de otras carreras es una manera de evitar que los jóvenes se encierren dentro de los muros de su profesión; y de abrir, por consiguiente, su conciencia hacia asuntos y problemas distintos y nuevos. Y se piensa entonces que la Formación General es eso: llevar materias de otras carreras.

Esta idea no es del todo descaminada, pero ha de notarse que en un sentido absoluto resulta inexacta. El seguir asignaturas de otras carreras no siempre es posible, porque a menudo su complejidad y sus detalles son obstáculos insalvables para su comprensión. De esta suerte sólo aquellas materias generales, o que ofrezcan una visión sinóptica de otros campos disciplinarios, pueden ser adecuadas para conducir los espíritus de los alumnos más allá de las fronteras de su profesión. Pero las citadas materias, por su carácter, aunque resultan próximas al sentido de la Formación General, no son estrictamente pertenecientes a ella. Son materias que pueden tildarse de cuasi integrantes de la Formación General, pues no presentan los problemas fundamentales del hombre y del mundo, sino asuntos importantes pero puntuales y de difusión propios de otras carreras.

\section{F. CONCLUSIÓN}

Todo lo precedente nos conduce a ponernos a distancia frente a tres maneras de visualizar la Formación General:

i) La concepción remedialista, que juzga a la Formación General como propia de la Secundaria y que le ve, en los claustros universitarios, como supliendo las deficiencias de la etapa escolar.

ii) La concepción Propedéutica que la confunde con los verdaderos cursos propedéuticos que toda profesión requiere. Pretende que la Formación General sirva a las carreras, desnaturalizando su esencia.

iii) La concepción suplementarista, que ve en la Formación General un recurso para abrir ventanas en cada profesión, ventanas que hacen posible echar una mirada a otras carreras. 
La concepción remedialista se dirige atrás, a la etapa previa; la concepción propedéutica se dirige hacia delante, hacia los cursos específicos de cada carrera, hacia otras carreras. Ninguna de estas concepciones se centra en la Formación General como tal y, por tanto, esa formación se les escapa de las manos.

\section{BREVE DESCRICIÓN DE LA FORMACIÓN GENERAL}

Hemos manifestado que la Formación General tiene una parte periférica y otra parte medular.

\section{A. LA PERIFERIA DE LA FORMACIÓN GENERAL}

La parte periférica la conforman aquellos conocimientos y destrezas que contribuyen a que el alumno universitario asuma dicho carácter. Se trata de asignaturas y talleres que le abren una visión de sí mismo como actores de su vida y su aprendizaje en la Universidad, nivel al que ha accedido y que no es igual a los de la etapa escolar. Veamos su posible composición:

i) Talleres comunicacionales

En primer término se halla el uso de la propia lengua. La Universidad tiene la lengua hablada y escritura como instrumento esencial de la vida académica. Con ella se expone, se analiza, se discute; se presentan las investigaciones; se leen los libros fundamentales. Resulta inconcebible que la mayoría de las carreras excluyan la lengua de sus currícula. Pero así se entiende que los jóvenes que llegan mal de la Secundaria en lo que respecta al uso de la lengua egresan luego de la Universidad con el mismo bajo nivel que alcanzaron en la Secundaria. Y no se pretende insinuar que la Universidad posee la función de llenar los vacíos de la etapa escolar. Absolutamente no. La Universidad tiene ante la lengua su propia responsabilidad, que no puede ni debe eludir. La primaria enseña al niño a leer y escribir; la Secundaria enseña(o debería enseñar) a entender lo que el adolescente lee y escucha. A la universidad le corresponde enseñar al joven a leer y escuchar analítica y críticamente y es posesionarse del vocabulario académico y su atmósfera. El no hacerlo priva a los alumnos de las antenas que les hacen posible captar y decepcionar lo que existe y discurre en el mundo de las disciplinas científicas.

Y después no es, por ciento, aquellos cursos de "Lenguaje y Comunicación" que algunas Universidades poseen. Dichos cursos con sus incursiones en la Lingüística no contribuyen un ápice al manejo del idioma ni a la comprensión de los textos universitarios. Luce risible que alumnos que no saben expresarse adecuadamente ni han alcanzado la actitud crítica para comprender los libros 
ni las exposiciones tengan que memorizar superficiales presentaciones de las teorías de Saussure o de Chomsky.

El tratamiento del lenguaje debe realizarse en talleres donde se redacte, haya elocución oral, se sumerja a los alumnos en lecturas y en las tareas de análisis y comprensión. La información gramatical y lingüística debe ser sólo subsidiaria a este enfoque, pero no central ni exclusiva.

Algo parecido equivalente ha de representar la adquisición de un idioma extranjero. Asimismo, la matemática, no como operativa y cúmulo de fórmulas y demostraciones, sino visualizándola como un lenguaje preciso que permite expresar relaciones en todos los ámbitos del quehacer humano.

Finalmente hay que considerar el uso de este otro lenguaje que las computadoras permiten hoy día.

ii) Asignaturas de auto-reflexión

Estas son las asignaturas que estudian diversas capacidades humanas que los alumnos universitarios deben de algún modo percibir, aunque sea parcialmente: la Lógica (la capacidad de pensar), la Metodología del Aprendizaje (la de aprender), la Teoría del conocimiento (la de conocer), la sicología de la Vida cotidiana (la periferia de nuestra vida anímica de todos los días). No se pretende, como se ha dicho que se programen todas estas materias, pero sí alguna (o algunas), según la Universidad estime conveniente.

\section{B. EL NÚCLEO DE LA FORMACIÓN GENERAL}

\section{i) Las materias Antropocéntricas}

Son las que reputamos fundamentales y eje de la Formación General. En todas ellas mora la figura del hombre y examina su relación con el universo, con su vida biológica, con los demás hombres, con su país. Son cursos complejos, multidisciplinarios, no fáciles de armar y de enseñar. Son cursos que no pueden ubicarse en el primero ni en el segundo o tercer semestre de una carrera, sino que deben escalonarse del cuarto hasta el décimo semestre, porque entonces los alumnos han madurado y han obtenido información más vasta.

Para describir un solo curso de este fruto, a saber, el relativo al universo físico, diremos que no es una asignatura Física más o menos general. No se trata de hablar del mundo temporo-espacial a secas.

Lo que se quiere es mostrar cómo el hombre ha lidiado con el universo para captarlo en su estructura más esencial y cómo esto ha devenido 
paulatinamente hasta forjar la imagen que hoy ha logrado. No es un presentar hecho exteriores sucesivos, sino un proceso de reflexión en el que ese avizora cómo la mente humana va hilando los hechos hasta alcanzar visiones coherentes de la realidad.

Dentro de este curso, si tomamos un solo eslabón como ejemplo, el de Copérnico, hay que mostrar los principios subyacentes a su teoría heliocéntrica, como el de simplicidad de la naturaleza surgida en la Edad Media y el estético, y mostrar en qué difería del sistema tolemarico y científicas que el heliocentrismo despertaba. Este era más sencillo que el egocéntrico, pero era menos exacto; y aunque nos daba otra imagen posible del universo en cuanto astronómico contradecía la física del momento; y, lo más serio, no podía explicar satisfactoriamente por qué los movimientos en nuestro planeta no se deformaban, puesto a que la tierra estaba en movimiento (objeción que sólo pudo responder muchas décadas más tarde con el principio de relatividad de Galileo). Como puede apreciarse se combinan armoniosamente datos de la astronomía, de la cosmología, de la física, de la historia de la ciencia, de la gnoseología y de la epistemología, a fin de sorprender el derrotero de la conciencia del hombre en su esfuerzo por sacar a la luz la estructura de este universo misterioso en torno nuestro. $Y$ es cosa ésta que a todos compete: al que va a ser físico, al que será ingeniero, o músico, economista, educadores, a todos los profesionales, si van a ser más que puros profesionales, es decir hombres cultos, sintonizados en su época.

\section{ii) Las Materias Suplementarias}

Como se indicara más arriba, las materias suplementarias (es decir, materias de otras carreras con la adecuada generalidad para no atosigar a los alumnos con detalles innecesarios) se encuentran próximas a la Formación General $y$, a nuestro criterio, pueden ofrecerse a los alumnos con carácter electivo. Ciertamente no cabe que sustituyan a las materias antropocéntricas, sino constituyen posibilidades adicionales.

Son muchas las asignaturas que pueden constituir este rubro y sólo como muestra listamos algunas: El código genético, la evolución de Darwin y hoy.

Etnocentrismo y racismo, los pueblos marginados, Economía y Desarrollo, la pobreza en América Latina, la tercera vía, Los derechos humanos, la Situación de la Mujer, Siglo de Oro Español, Literatos contemporáneos sudamericanos, Agricultura e Industria. El mundo de los servicios, el mundo de la información, etc. 


\section{LA ADMINISTRACIÓN DE LA FORMACIÓN GENERAL}

\section{A. UNA UNIDAD ACADÉMICA PARA ELLA}

El conjunto de materias comprendida dentro de la Formación General, particularmente las que son obligatorias, no puede ser entregado a las distintas Facultades y Escuelas.

Con ello se perdería unidad, se desembocaría en real behetría, contradiciéndose la naturaleza de la Formación General. Además la experiencia muestra hasta la saciedad que cuando los cursos de Formación General llegan a ser administrados por las diferentes facultades y Escuelas, poco a poco los profesores de estas van dándole a dichos cursos el sesgo de sus carreras, y eliminando aquellas asignaturas que no pueden adecuarse de esa manera.

La garantía de que la Formación General no va a deformarse y ha de incluirse necesariamente en los currícula de todas las carreras es: (a) Estableciéndola formalmente en la Política Curricular de cada universidad; y (b) Creando una unidad académica que se haga cargo de tales materias.

Esa unidad puede recibir diferentes nombres: Facultad de Estudios Generales, como en su tiempo en la Universidad de Puerto Rico, O en la Universidad Simón Bolívar, de Caracas; o una Dirección General, en la Universidad San Martín de Porres, en Lima; Dirección de Materias Comunes, como en la Universidad Nacional San Luis Gonzaga, de Ica; Departamento de Formación General, como en la Universidad Rafael Urdaneta, en Maracaibo.

Hacemos la salvedad de que si bien estas unidades académicas existen con esos diversos nombres, no siempre administran materias que son realmente de Formación General. En la Facultad de Estudios Generales de Puerto Rico las asignaturas eran, en efecto, de Formación General. La facultad de Estudios Generales de la Universidad de Simón Bolívar comprende materias de Formación General y muchas suplementarias. No parece que la dirección respectiva de la Universidad San Martín de Porres comprende al lado de materias de Formación General, una serie de cursos que son básicos o mejor propedéuticos. La Dirección pertinente de la Universidad San Luis Gonzaga administra todos los cursos de Formación General y asimismo las Actividades no cognitivas y los cursos de Gestión, que son comunes a todas las carreras (por eso se llama Dirección de Materias Comunes). 


\section{B. LA DISTRIBUCIÓN DE LA FORMACIÓN GENERAL EN EL CURRÍCULO}

Es usual - por imitación de los Estados Unidos - el ubicar la Formación General en los tres primeros semestres de las carreras. En nuestro país, por ley se estableció en los cuatro primeros semestres de las carreras en todas las Universidades. Esta es la denominada "Estructura Horizontal" de la Formación General, y en nuestro concepto es profundamente equivocada.

Y lo es, porque en esencia la Formación General aspira ampliar los horizontes espirituales de los futuros profesionales. Y esto no se puede lograr si la Formación General ocupa los primeros semestres (casi siempre dos) y todos los semestres restantes se dedican a la Formación Profesional, con prescindencia absoluta de la Formación General. Esta censura absurda no conducirá a iluminar los largos semestres profesionales y profesionalizantes con siquiera un leve resplandor de la Formación General. Los alumnos no lograrán vincular el correcto periodo inicial concentrado en la Formación General con el largo período subsecuente en que la Formación General se eclipsa por entero.

Y no sólo es válido lo dicho, sino que las materias más profundas de la Formación General, a saber, las antropocéntricas, son en realidad inaccesibles para los jóvenes recién salidos de la etapa escolar. Carecen de la información y de la madurez para comprenderlas. $Y$ entonces ocurre una de dos: o los profesores bajan el nivel de las mismas, y los alumnos entienden menos y resultan para ellos meros compendios que poco les dicen; o los profesores mantienen el nivel adecuado y los alumnos se ven obligados a memorizar. En ambos casos los propósitos de la Formación General se pierden, y, en última instancia, los jóvenes no ven la razón de haber pasado dos o tres semestres en los cursos de Formación General.

Aparte de estos dos hechos atañederos a la naturaleza de la Formación General, se dan otras circunstancias, que resultan negativas para la estructura horizontal.

i) Los alumnos, que en su inmensa mayoría ingresan pensando en la carrera escogida por ellos, se encuentran con una serie de asignaturas de Formación General no relacionadas con la profesión elegida. Se someten a lo dispuesto por la institución universitaria, pero internamente quedan decepcionados. Se logra de este modo en ellos una actitud de incomodidad, peor aún, de íntimo rechazo a la Formación General, que es lo opuesto a lo que la Universidad desea promover.

ii) La situación se agrava si las Facultades y Escuelas Profesionales aprovechan el periodo de la Formación General para disminuir el número de alumnos que 
tengan acceso a sus aulas. Esto se obtiene cuando dichas Facultades y Escuelas determinan que ningún alumno puede iniciar los estudios profesionales. Semejante prescripción, como se comprende, no se dicta por amor a la Formación General. Y resulta grave porque la Formación General queda entonces convertida en un filtro que impide el paso hacia los semestres de Formación Profesional. Con tal medida la etapa previa de Formación General se transforma en un ciclo de represamiento, lo cual acentúa el disgusto de los estudiantes. Ello los aleja aún más de la Formación General.

iii) El rostro negativo que adquiere la Formación General se vuelve mayor, si, como ha ocurrido con frecuencia, las Facultades y Escuelas comienzan a contar sus semestres a partir del inicio de los estudios profesionales. Ese es el III Semestre en el cual se inician los estudios profesionales pero para ellas es el I Semestre. Los ciclos previos de Formación General no los consideran parte de las carreras. De esta manera se completa una sutil satanización de la formación General y se esfuman por completo los elevados propósitos por los cuales fue incorporada a los currícula universitarios.

iv) En los estudios profesionales existen a veces secuencias de asignaturas extensas que no pueden cumplirse en los ocho o siete ciclos que les han sido asignados, pues la Formación General tiene los semestres previos. En tal sentido, la estructura horizontal de la Formación General perturba grandemente dichas secuencias. A veces se ha intentado salvar este obstáculo fijando algunos cursos básicos (o propedéuticos) de la Formación dentro del ciclo de la Formación General. Pero este remedio, como hemos visto, resulta a menudo peor que la enfermedad, pues se tiende a desarrollar esas materias básicas sin conexión con las carreras, a pesar de su carácter propedéutico.

v) En ocasiones se sostiene como argumento a favor de la estructura horizontal de la Formación General que es un período en que los jóvenes confirman o desechan la selección que hubieran efectuado de una carrera, para iniciar así sus estudios profesionales con paso más firme. Empero, semejante idea luce no pertinente por dos razones, Primero, la Formación Profesional ab ovo, no se halla relacionada con ninguna carrera. No posee en ella nada que pueda disuadir o consolidar las decisiones de los alumnos. Por esencia la Formación General no ostenta propósito vocacional y mal se hace en asignársele esa función, la cual no puede cumplir. En cambio, si la Formación Profesional comenzara desde el I Semestre, lado a lado con la Formación General, tales cursos profesionales les darían a los alumnos un atisbo, el sabor de la profesión que seleccionaron y eso si serviría para confirmarlos o para decepcionarlos respecto a su decisión. Segundo, si, como es más grave, se ha determinado 
que los alumnos escojan carrera después del ciclo de Formación General (sin que haya habido realmente nada vocacional porque ello no es propio de la Formación General) se generaría una situación espinosa: la posibilidad de que los alumnos -ya dentro de la Universidad- masivamente escojan una carrera en particular. Así ocurrió hace años en dos Universidades peruanas, en las cuales se estableció el sistema de elegir carrera tras concluida la Formación General: el $80 \%$ de los estudiantes pidió Medicina.

vi) Los alumnos que ingresan a la Universidad procedentes de la etapa escolar son mayoritariamente inmaduros. Un ciclo inicial de Formación General en manos de docentes inescrupulosos se presta para que se realicen, en las asignaturas, acciones de adoctrinamiento, como ha ocurrido en varios países, inclusive el nuestro. En cambio, una Formación General distribuida a lo largo de 10 o 12 semestres de Estudio encontrará a los alumnos mejor informados y más maduros y ellos mismos podrán detectar qué profesores quieren manipularlos y quiénes presentan los problemas con espíritu científico.

Todas estas razones, algunas más importantes y otras menos importantes, apuntan a una conclusión: la estructura horizontal de la Formación General es altamente inconveniente. La Formación General debe impartirse en forma diagonal, lado a lado de la Formación Profesional. No es posible, yendo al fondo de las cosas, que la Formación General se dé al comienzo del nivel universitario, cuando las capacidades de los alumnos están recién desplegándose, y que después nunca más se vuelva a ver. Es la mejor manera de impartir una preparación realmente profesionalizante, con un endeble barniz no profesional. La Formación General, atendiendo a su profundo significado, debe ser el acompañante permanente de la Formación Profesional. Y ello solamente es posible con la estructura diagonal.

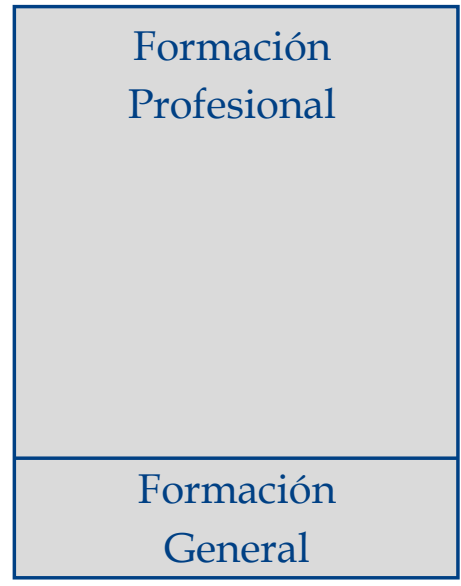

Estructura General

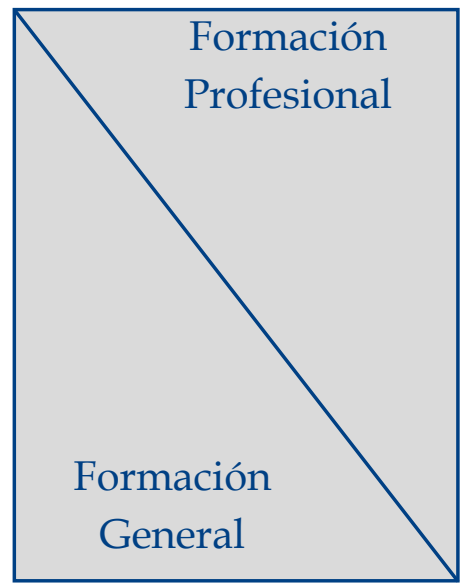

Estructura Diagonal 


\section{PRIMERA ADVERTENCIA}

El que hayamos definido varios tipos de asignaturas y talleres dentro de la Formación General, Y el que hayamos sugerido diversos componentes dentro de cada tipo no significa que las Universidades quedan obligadas a introducir la totalidad de esta Formación General, así descrita, en sus currícula.

Cada institución universitaria ha de examinar el vasto terreno de Formación General y tomar de él lo que juzgue apropiado. Después de todo, así como en la Formación Profesional, cada Universidad ha de poner su sello en la Formación General.

Lo que sí cabe esperar es que en lo genérico se cubra todo el espectro de la formación General es decir, no pueden dejar de haber talleres comunicacionales y cursos de autorreflexión y antropocéntricos. Cuáles y cuantos es materia a resolver por cada institución. En principio, la Formación General no debe ser inferior al 12\% del tiempo curricular y puede llegar al 20\%. Obsérvese que hablamos del "tiempo curricular" y no de créditos, los cuales constituyen un sistema de medición convencional y puramente artificial. Lo real e inconmovible es el tiempo curricular, computado en horas semanales por semestre. La suma de las horas semanales de todos los semestres de una carrera (hrc) es el tiempo curricular de la misma.

\section{SEGUNDA ADVERTENCIA}

La segunda cuestión a considerar, a fin de desecharla, es la que a veces surge en ciertos sistemas universitarios, a saber, que así como se piensa en homogeneizar los currícula de todas las carreras que son iguales en las distintas Universidades, asimismo se piensa en homogeneizar la Formación General en todas ellas. Esta tendencia hacia el currículum único, trasladada a la Formación General, es nefasta para el sentido de las Universidades y suscrita las mismas objeciones que la idea del currículum único.

Esta pretensión, acariciada por algunas Asociaciones (también denominadas "Núcleos" en otros países) de las Facultades o Escuelas, o carreras iguales, y que quiere que los currícula (excepto un 15\% o un 20\%) sean los mismos en todas las Universidades, se revela como negatoria de la libertad de que deben disfrutar las instituciones universitarias para organizar los proceso de formación de sus estudiantes. Ya no tendrían la posibilidad de delinear currícula propios, sino estarían sujetas a decisiones que llegaran de fuera. La personalidad, loas características singulares, a que cada Universidad de hecho ha aspirado y aspira a ostentar, desaparecería bajo una ominosa y gris uniformidad. 
Y peor es que lo más trascendente, a saber la creatividad de una Universidad para trazar la formación de sus alumnos, tanto en el contexto de cada profesión, como en lo referente a la Formación General, naufragaría por completo. Establecidas semejantes formaciones únicas, la idea de un cambio posible seria poco menos utópica, pues habría que convencer para ello a todas y cada una de las instituciones del sistema universitario. Y siendo tal cosa difícil, se ingresaría en un periodo de rutina y repetitividad escalofriantes.

\section{E. TERCERA ADVERTENCIA}

La acreditación de las carreras muchas veces es utilizada por quienes propician currícula únicos, con el fin de imponer la uniformidad a todas las instituciones en el país. Pero semejante intención es básicamente equivocada. La acreditación no es un proceso para instaurar una suerte de yugo curricular a las Universidades. La acreditación es un proceso mediante el cual se compulsa si la formación que una Universidad brinda a sus alumnos posee mínimo de solidez que espera de una institución universitaria, cualquiera que sea su concreto ordenamiento curricular; desaparecería si tuviera que someterse en un currículo único. Pero lo esencial, por otra parte, es que la acreditación (cosa necesarísima) no tiene por objeto uniformizar los currículos.

Atribuirle ese propósito es distorsionar la acreditación, pues ella apunta en otra dirección: respetando la creatividad de cada institución universitaria, la acreditación determina si la preparación dada a los alumnos es satisfactoria o no. Y no debe olvidarse que toda acreditación comienza por una autoevaluación, write it together de cada universidad y que el segundo paso, que es la evaluación por una entidad externa, confirma o desecha la autoevaluación, pero de ningún modo impone un currículo único, que sea igual en su totalidad o parcialmente a los de otra u otras Universidades. Acreditar es calibrar el grado de excelencia de la preparación que una institución universitaria ofrece, pero no constituye un procedimiento para imponer o prescribir determinado currículo. 